This is an electronic reprint of the original article. This reprint may differ from the original in pagination and typographic detail.

Author(s): Palviainen, Åsa; Protassova, Ekaterina; Mård-Miettinen, Karita; Schwartz, Mila

Title: $\quad$ Two languages in the air : a cross-cultural comparison of preschool teachers' reflections on their flexible bilingual practices

Year: $\quad 2016$

Version:

Please cite the original version:

Palviainen, Å., Protassova, E., Mård-Miettinen, K., \& Schwartz, M. (2016). Two languages in the air : a cross-cultural comparison of preschool teachers' reflections on their flexible bilingual practices. International Journal of Bilingual Education and Bilingualism, 19(6), 614-630. https://doi.org/10.1080/13670050.2016.1184615

All material supplied via JYX is protected by copyright and other intellectual property rights, and duplication or sale of all or part of any of the repository collections is not permitted, except that material may be duplicated by you for your research use or educational purposes in electronic or print form. You must obtain permission for any other use. Electronic or print copies may not be offered, whether for sale or otherwise to anyone who is not an authorised user. 
Two Languages in the Air: A Cross-cultural Comparison of Preschool

Teachers' Reflections on their Flexible Bilingual Practices

Åsa Palviainen ${ }^{1}$

Department of Languages, University of Jyvaskyla, Jyvaskyla, Finland

Ekaterina Protassova ${ }^{2}$

Department of Modern Languages, University of Helsinki, Helsinki, Finland

Karita Mård-Miettinen ${ }^{3}$

Department of Scandinavian Languages, University of Vaasa, Vaasa, Finland

Mila Schwartz ${ }^{4}$

Department of Research and Evaluation Authority, Oranim Academic College of

Education, Haifa, Israel

Addresses for correspondence:

${ }^{1}$ Department of Languages, P.O. Box 35, FIN-40014 University of Jyväskylä, Finland e-mail address: asa.palviainen@jyu.fi (main author)

${ }^{2}$ Department of Modern Languages, P.O. Box 24, FIN- 00014 University of Helsinki, Finland

e-mail address: ekaterina.protassova@helsinki.fi

${ }^{3}$ Department of Scandinavian Languages, University of Vaasa, P.O. Box 700, FIN-

65101 Vaasa, Finland

e-mail address: Karita.Mard-Miettinen@uwasa.fi 
${ }^{4}$ Department of Research and Evaluation Authority, Oranim Academic College of Education, Kiryat Tivon, 36006, Israel e-mail address: milasch@post.bgu.ac.il

Acknowledgements: This work was supported by The Academy of Finland [Grant No 266850] and The Swedish Cultural Foundation in Finland [Grant No 13/1118-1303]. 


\section{Two Languages in the Air: A Cross-cultural Comparison of Preschool Teachers' Reflections on their Flexible Bilingual Practices}

Bilingual preschool education is under researched compared with bilingual school education. There is also a lack of research on bilingual preschool teachers' agency and how they negotiate between two languages in the classroom. We examined the language practices of five bilingual preschool teachers working within three different socio-linguistic settings, in Finland (Finnish-Swedish and Russian-Finnish contexts), and Israel (an Arabic-Hebrew context) and interviewed the teachers about their use of languages in the classroom. We found that in each context the teachers reported modifications to an initial bilingual education model over time: from a strict separation of languages, to flexible bilingual practices. A thematic analysis of the contents of the teacher reflections as they emerged through interviews revealed five shared categories:

(a) the flexible use of two languages; (b) responsible code-switching; (c) contextual and linguistic supports; (d) adjustments for individual children; and (e) role-modelling. Despite the different settings and sociolinguistic conditions, the similarities in teachers' practices and the rationale they gave for applying flexible bilingual practices were significant. The shared practices across contexts may have important implications for bilingual education.

Keywords: bilingual preschool education; flexible bilingual practices; teacher agency; early childhood bilingualism; language attitudes; code-switching

\section{Introduction}

The aim of this study was to compare five teachers' reflections on their own language practices and the challenges they faced in implementing bilingual language education within three contexts of preschool education in Finland (Finnish-Swedish and RussianFinnish contexts), and Israel (an Arabic-Hebrew context). Ricento and Hornberger (1996) as well as Menken and García (2010) place teachers at the very heart of language policy-making. However, little research attention has been paid to providing bilingual teachers with any deeper understanding of their own agency and their critical role in negotiating, constructing and reconstructing classroom language practices. This is 
especially true for the context of preschool education and young children's essential developmental and social needs.

As Heller (2007) has pointed out, language practices are inseparable from beliefs about languages and attitudes towards them in the surrounding society. For this reason we also considered it important to examine how the teachers' reflections were embedded in the specific educational and socio-political context in which they expressed them, and which possibly had an impact on their language practices. The comparative contexts chosen for this study, Finland and Israel, are both bilingual countries, where Finnish and Swedish, and Hebrew and Arabic, respectively, are official languages. However, for socio-political and historical reasons, the minority languages Swedish and Arabic are differently presented in the linguistic landscape of these countries and also differ considerably in terms of their socio-cultural status (see on the Finnish context, Lindgren, Lindgren, and Saari 2011; and on the Israeli context, Amara 2002). After Finnish and Swedish, Russian has the greatest number of mother tongue speakers in Finland. As an immigrant language, however, Russian in Finland does not have the same strong position as Finnish and Swedish (e.g., Lähteenmäki and Pöyhönen 2015). Differences in terms of status ought to have consequences on bilingual preschool teachers’ aims and language practices and on how these languages are used and acquired by children who speak the majority language (e.g., Shohamy 2010).

The research question to be addressed in the current study concerns how the teachers in the Finnish-Swedish, Russian-Finnish and Arabic-Hebrew preschools describe and explain their language practices. The data are examined and compared across the three different and unique settings with the aim of identifying common issues and bilingual educational practices in the five teachers' reflections. 
In the following sections, before moving on to our own study, we will present a brief overview of the main bilingual education models and look at research on how teachers in bilingual classrooms have responded to challenges in the realization of these models by constructing and negotiating bilingual spaces and adopting flexible language practices. We will also present a brief description of the sociolinguistic settings that are the context of the current study.

\section{Theoretical Background}

\section{Bilingual Education Models}

There is a wide range of educational models which may be referred to as bilingual (Baker 2009). García (2009, 310) distinguishes between two main models: those built on strict separation and those based on flexible use of the languages. Within a bilingual model of strict separation, the languages are separated by time (e.g. teaching through one language in the morning and another language in the afternoon), by teacher (one person - one language, monolingual teaching by each teacher), by place (separate classrooms for teaching in each language) or by subject (one subject is taught through one language, e.g. science in Spanish and mathematics in English), or a combination of these. An actual example of a bilingual model in which the teaching is based on strict separation is one-way and two-way immersion education. In immersion programmes, separation is used to enhance L2 acquisition by helping young beginning L2 learners to identify each language more easily and by motivating them to start using the new language more readily. Student talk in immersion classrooms may, however, be bilingual or multilingual, which has also been shown to be advantageous for students' learning (Swain and Lapkin 2013). Recently, on the other hand, Cummins (2014) as well as Swain and Lapkin (2013) have called for planned, intentional cross-linguistic 
pedagogy for immersion programmes rather than separation of the languages as two isolated systems.

In a flexible bilingual model, two or more languages are used in combination in the bilingual classroom (García 2009). The concurrent use of the two languages may be applied by teachers or by children or by them both (Creese and Blackledge 2011). One core classroom practice in a successful flexible multiple model is responsible codeswitching, in which teachers 'monitor both the quantity and the quality of their codeswitching’ (García 2009, 299). According to García, ‘[s]chools that adopt multiple bilingual teaching have a clear language policy that includes not only the development of bilingual proficiency, but also ... plurilingual values of today - multilingual awareness and linguistic tolerance’ (García 2009, 309; italics García’s own). This bilingual education model could be viewed as a realization of truly bilingual pedagogy (Arthur and Martin 2006; Creese and Blackledge 2010; Cummins 2005).

In recent years, bilingual education models like language immersion programmes that separate languages and educate monolingually for bilingualism have been widely criticized and challenged. García (2013, 157), for example, has pointed out that 'although bilingual education programs that separate language ... might work well for language majorities that are adding additional languages of prestige with power similar to their own', language separation often builds on the assumption that all children have a similar language background, and is thus not sensitive to multilingual minority language students in the classroom. For such reasons, Weber (2014) and others call for more flexible multilingual practices in classrooms, although he also warns against 'romanticizing' flexible bilingual practices and argues that it is crucial to 'set up an ethical and responsible theory of flexible multilingual education' (Weber 2014, 7). 


\section{Negotiation Processes in Bilingual Classrooms}

Hitherto, few studies have focused directly on examining teachers' attitudes to a policy of strict language separation, and how teachers negotiate between two languages in the classroom and apply diverse flexible bilingual practices (see however Conteh 2007; Gort and Pontier 2013; Hickey, Jewish, and Baker 2014; Swain and Lapkin 2013). Lemberger (1997), in a comprehensive study of bilingual teachers' reflections on their experience in the US, concluded that 'literature written for teachers tells them what they should do without asking them about their own experiences.' (Lemberger 1997, 6).

In the study of Hickey, Jewish, and Baker (2014), teachers in a Welsh immersion preschool reported on the need to negotiate between the demand that they should use Welsh at all times and the children's diverse linguistic backgrounds. The teachers translated Welsh into English for young children with a predominantly English background to facilitate their understanding and reduce distress. However, there was tension between the need to switch from Welsh to English and the commitment to full immersion in Welsh. In addition, the study showed that the teachers were not sure how much translation was appropriate in a full immersion programme. Swain and Lapkin (2013) reported that individual immersion teachers applied different practices in their use of students' L1 in the classroom. The practices of the four primary and secondary school teachers in Swain and Lapkin formed a continuum from basically no use of the students’ L1 to frequent use. Unlike the teachers in Hickey, Jewish, and Baker (2014), the teachers in this study did not comment on whether or not their practice was appropriate in an immersion context.

Gort and Pontier (2013) also focused on how teachers used different negotiating processes to reconcile the tension arising from implementing the official policy of language separation while at the same time addressing children's needs. Their analysis 
of Spanish/English preschool teachers' language practices provided insights into such flexible language practices as code-switching, tandem talk (i.e., a pair of teachers coordinates the use of two languages to maintain the use of monolingual speech in a bilingual conversation) and scaffolding techniques (e.g., use of gestures, and visual reinforcement of concepts), which were explicitly used to support children's engagement and facilitate children's comprehension.

Menken and García $(2010,1)$ asserted that 'regardless of the type of policies or the educational context in which a policy text comes to life in the classroom, there is typically space for policy negotiation in classroom practice’. Such a process of negotiation can be seen in different models of bilingual education across the world. Although an increasing number of studies recently have examined flexibility in language use in bilingual school settings (e.g. García and Wei 2014), few studies have been directed towards bilingual preschool classrooms. Before moving on to the present empirical study, we will briefly describe the sociolinguistic context of the preschools in the two countries, Finland and Israel.

\section{The Finnish and Israeli Contexts}

\section{The Finnish Context}

Finland is a bilingual country where Swedish by status is an official language equal to Finnish, but a minority language in terms of numbers of speakers: at the end of 2014, 89.3 \% of the population were registered as Finnish speakers, $5.3 \%$ as Swedish speakers (Official Statistics of Finland 2014). Finland has a system of parallel monolingual education, meaning that schools are administratively either Finnish or Swedish medium. The other national language (Swedish in Finnish medium schools, Finnish in Swedish medium schools) is an obligatory subject from the age of 12 years. 
Although attitudes among the majority language speakers towards Swedish today are generally positive, there are certain political movements arguing for reducing the status and space of Swedish in Finland (e.g. Lindgren, Lindgren, and Saari 2011; Hult and Pietikäinen 2014).

Today, $1.3 \%$ of the population are registered as Russian speakers. Russian can be studied as a foreign language or as a mother tongue in some Finnish schools and there are about 20 Russian-medium preschools in Finland. In recent times, there have been debates on whether the Finnish authorities should do more to promote the rights of the fast-growing numbers of Russian speakers and the teaching of Russian (Lähteenmäki and Pöyhönen 2015).

Debates about language education policy are only rarely and implicitly concerned with preschool education. The ideology of separating languages in both educational and family contexts is, however, strong in Finland, especially as regards Finnish and Swedish. There is currently a lively debate going on about whether bilingual Swedish-Finnish schools should be established as an alternative to monolingual Swedish or Finnish schools (for a comprehensive overview, see e.g. Boyd and Palviainen 2015). However, to date no such school has been established.

\section{The Israeli Context}

Arabic and Hebrew are the two main languages spoken in Israel. Although Arabic is spoken by a minority of the Israeli population, it is considered an official language alongside Hebrew (Amara 2002). Most Arab-Israelis understand and speak Hebrew, and use it at work and in other settings. Although the study of Arabic is obligatory in the Jewish secular school curriculum from year five to year ten (Amara 2002), the level of competence of young Jewish people in Arabic is relatively low. 
Bilingual Arabic-Hebrew education was established in the early 1990s to promote the mutual acknowledgement, tolerance and respect of Arab and Jewish children. In terms of language policy, these Arabic-Hebrew bilingual educational settings were set up to challenge the segregated monolingual and monocultural education system in the country: Israel has separate Hebrew-speaking and Arabicspeaking education systems and Arab and Jewish children are therefore educated in different schools. The bilingual education is coordinated by the Center for Bilingual Education, under the aegis of the Ministry of Education, which supervises the pedagogical aspects of the network as well as the curriculum in each target language. Schools have been consistent in choosing teaching and management staff that represent both groups equally. Each class has two language teachers, one Arabic and one Jewish, each of whom uses their own native language. It is up to the individual teacher to decide whether or not they want to teach in these educational settings, just as it is the parents' personal choice to send their children to this type of school (Bekerman and Tatar 2009).

\section{Methods}

\section{Research Settings}

This study included three preschool settings in Finland (Finnish-Swedish and RussianFinnish contexts), and Israel (an Arabic-Hebrew context). These are described in turn below and a summary of the settings can be found in Table 1.

\section{The Finnish-Swedish Setting}

For the Finnish-Swedish context, a Finnish-medium preschool in a Finnish-speaking area in central Finland was chosen (for a detailed description of the Finnish educational and preschool system, see Bergroth and Palviainen, this volume). In 2012 the principal 
of the preschool initiated a language project in Swedish for a class of monolingual Finnish-speaking children, to introduce them to Swedish. The aims were to make the children familiar with Swedish and contribute to positive attitudes. One bilingual teacher was appointed to work on this. In the first year of the project there were three teachers involved (the bilingual teacher and two Finnish-speaking teachers) and 22 monolingual Finnish-speaking children aged between 1 and 6 years. In the second year the group expanded to include 28 children and another bilingual teacher joined the project. The children were being prepared to go on to attend a Finnish medium school. The bilingual teacher(s) applied a 50:50 principle of language use with the children whereas the Finnish-speaking teachers predominantly used Finnish.

\section{The Arabic-Hebrew Setting}

In the Israeli context, our focus was on a bilingual Arabic-Hebrew speaking preschool in the centre of the country. The preschool was established in 2004 and applied flexible bilingual pedagogy. One important mission of the preschool was to facilitate intergroup contact and enhance positive attitudes and relations between Arabic and Jewish children (Bekerman 2005). At the time of data collection there were 19 children in the class, 5-6 years old, of whom approximately $60 \%$ were Arabic (L1) speaking and $40 \%$ Hebrew (L1) speaking. The teachers aimed to use Arabic and Hebrew in similar amounts. The preschool was part of a bilingual elementary school in which the children were expected to continue their schooling for the next six years.

\section{The Russian-Finnish Setting}

The Russian-Finnish preschool examined was located in the Helsinki region of Finland and established in 1990 in association with a Russian-Finnish school. The purpose of 
the preschool was to encourage the bilingual education of children coming from Finnish-speaking, Russian-speaking or multilingual homes. At the time of the data collection, the preschool had a total of 98 children between 2 and 6 years of age, divided into five groups. The teachers in each group shared their duties so that for each group, one teacher was responsible for Russian language instruction, another for Finnish language instruction, and a third one, a bilingual teacher, made use of both languages in his or her work with the children. After this preschool, most children continued to a Russian-Finnish bilingual school. In the two groups examined here there were 35 children, about one third with a monolingual Russian background, one third with a monolingual Finnish background, and the remaining children with a bilingual FinnishRussian background.

[Table 1 near here]

\section{Participants}

Five preschool teachers representing the three settings were included in the study.

\section{Johanna}

Johanna, from the Finnish-Swedish setting, was a bilingual preschool teacher with 20 years' experience of Swedish-medium and Finnish-medium preschools in Finland and Sweden, as well as Swedish immersion preschools in Finland. She grew up in Sweden in a Finnish-speaking family and went to a mainstream Swedish school. She completed a lower degree in childcare in Sweden, moved to Finland, and completed a Bachelor's degree in the field of childhood education in a Swedish-medium university in Finland. She also enrolled in in-service courses on immersion education. By the time of the 
interviews she had lived and worked in a Finnish-dominated area of Finland for over 15 years.

\section{Aviva and Sokeina}

In the Arabic-Hebrew setting, the study participants were two preschool teachers: Aviva, a native Hebrew-speaking teacher, and Sokeina, a native Arabic-speaking teacher. The teachers started working together as a team from the establishment of the preschool in 2004. Both teachers obtained their teaching certificate from a teacher training college and had specialized in preschool and elementary school teaching. They had had no professional training in bilingual teaching and no professional experience in bilingual education prior to working in this preschool. However, they had professional supervision from an experienced bilingual teacher working in the Center for Bilingual Education. Aviva had more than 16 years' professional experience. Sokeina was an Arabic-speaking teacher with over 10 years' professional experience of elementary school as well as preschool teaching. Both shared a perception of the importance of the joint education of Arabs and Jews in order to encourage a positive relationship and mutual understanding.

\section{Tomi and Lena}

Two teachers from the Russian-Finnish preschool participated in the study. Tomi, Finnish by birth, spoke Finnish as his native language. He had graduated from the University of Kiev, where he had studied Russian. He had worked in the RussianFinnish preschool for 23 years, before which he had had some experience teaching children with special needs. At the time of the study, Tomi was working as a bilingual teacher at the preschool with a group of 4-year-olds. The second teacher in the study, Lena, was born in Russia and came to Finland 25 years ago to join her Finnish husband. 
She worked at the Russian-Finnish preschool as a teacher’s assistant, with special responsibility for teaching Russian. She had done her pedagogical training in Finland and had previous experience from a French-Finnish bilingual preschool. In addition to her native Russian, she knew Finnish and some English. She was working with a mixed age group of children (aged 2-5 years).

\section{Research Methodology and Data Collection}

The study is situated in the domain of studies of ideology, social practice and social organization. We applied a combination of linguistic and ethnographic methodology combining data such as observations, field notes and interviews with analysis of language practices (Rampton et al. 2004; see also Creese and Blackledge 2011; Maybin and Tusting 2011). The methodology allowed us to analyse the teachers' reflections on their language practices as fundamentally social phenomena, inseparable from the teachers' beliefs and attitudes about the place of the target languages in their society.

The data included observations as well as in-depth semi-structured interviews with the teachers in the three research locations. The data collection procedures differed to some extent across the settings (e.g. in terms of time span and regularity) but the procedures behind the semi-structured interviews - the main data source of the current study - were similar. First, ethnographic observations of the bilingual teacher/s interacting with the children in activities such as meals, small group interaction and circle time, were conducted. After this, the teacher/s watched video-recordings of the observation sessions and discussed their practices with the researchers (Gass and Mackey 2000). In these interviews, the teachers were asked to reflect on their own language behaviour, as observed in the collected data. The teachers were also asked about their professional experience, and their socio-linguistic as well as their educational background. 
The data from the Finnish-Swedish preschool were collected during two academic years, August 2012 to May 2014. The teacher was video-taped while interacting with the children for half a day on two different occasions (December 2012 and December 2013). Each of the two interviews with the teacher lasted for around 60 minutes and they were both conducted in Swedish and audio-taped. In Israel, ten videorecorded observation sessions were conducted in the kindergarten twice a month from April 2011 to November 2011. During the observation sessions the focus was on the teachers' language practices during their teaching as well as on their spontaneous communication with the children. Two interviews were held with each teacher during the research period (the first in May 2011 and the second in October 2011). The interviews lasted for 90 minutes each and were conducted in Hebrew and audiorecorded. As for the Russian-Finnish preschool, the researcher visited the preschool during one week in the spring of 2014. The researcher made field notes, video-taped 4 hours of interaction and, based on the observational data, conducted interviews with the teachers. The interviews were audio-recorded, lasted for about one hour each, and were carried out in Russian and English.

\section{Analysis}

In analysing the interview data we conducted thematic analysis based on the research question: 'How do the teachers in the Finnish-Swedish, Russian-Finnish and ArabicHebrew preschools describe and explain their language practices?'. Our particular aim was to identify the common themes and to do this we followed the steps proposed by Braun and Clarke (2006). Our identification of the themes was guided by the definition that a 'theme captures something important about the data in relation to the research question, and represents some level of patterned response or meaning within the data set' (Braun and Clarke 2006, 10; italics in original quote). 
The teachers' interviews were analysed in the following steps: 1) The interviews were transcribed and the transcriptions were translated into English; 2) The transcribed interviews were read, reread and discussed by the researchers; 3) Patterns in the data which addressed the research questions were identified and defined as possible themes and sub-themes; 4) The themes and sub-themes were reviewed by experts across the three research settings to increase the reliability of the thematic analysis we conducted; and 5) Decisions were made concerning the most illustrative examples of the teachers' reflections on their agency in constructing and reconstructing classroom language practices.

As a result of this process the following key themes of bilingual practices were identified:

(a) the flexible use of two languages;

(b) responsible code-switching (avoiding direct translation, using languages for different communicative purposes);

(c) contextual and linguistic supports;

(d) adjustments for individual children; and

(e) role-modelling.

These themes laid the foundation for our comparative analysis of how the five teachers across preschool contexts described and explained their language practices.

\section{Findings}

The key themes as extracted from the teacher interviews are here presented in turn. The section concludes with a summary of the findings. 


\section{The Flexible Use of Two Languages}

The teachers in all three settings reported that they had made modifications over time from previous use of a bilingual educational model built on language separation to a flexible bilingual model - and that they had done so actively and knowingly.

In the Finnish-Swedish classroom, the language activities were first labelled as language showers in Swedish for Finnish-speaking children, and the initial goals set up by the superiors were broad ('to familiarize children with Swedish'). The teacher, Johanna, was given the freedom to develop her own practices. She soon felt that the traditional language shower methodology as described e.g. by Mehistö, Marsh and Frigols $(2008,13)$, as single weekly or daily activities in a foreign language, was too 'mechanical' and did not promote the children's understanding. Instead of using the traditional language shower methodology, Johanna started to develop a flexible bilingual practice, alternating between Finnish and Swedish throughout the day while carrying out everyday activities. This practice was in tune with her belief in learning while doing, but at the same time it clashed with her previous personal and professional practice of separating languages by person, place or time. She often referred in the interviews to the adaptation required, explaining that it involved a major attitudinal change: ${ }^{\mathrm{i}}$

\footnotetext{
Johanna (the bilingual Finnish-Swedish teacher): this [=moving back and forth between the two languages] is something I used to have huge problems with because I have always thought one person one language one place one language I am bilingual myself I have always spoken Swedish to my children (.) and I have worked in Swedish medium preschools and I have worked in language immersion preschools so it has been completely (.) for me to understand that this is allowed (.) I had such big trouble [with it]
}

From the interviews it became evident that, contrary to her expectations, these 
monolingual children did not find her flexible bilingual language practices awkward or difficult. Johanna pointed out that it was important to encourage positive attitudes towards the Swedish language and Swedish culture in these majority Finnish-speaking children: 'this language [=Swedish] must not become a negative thing (.) it should be more of a fun and positive thing'. Still, she stressed in the interviews that the children's L1 Finnish was as important as their L2 Swedish: she wanted to treat the two languages equally (cf. Lewis, Jones, and Baker 2012, 659).

The aims of the bilingual education in the Arabic-Hebrew classroom were somewhat different from those in the Finnish-Swedish classroom, since there were children with Arabic as their L1 as well as Hebrew as their L1 in the same room and the idea was that both groups of children should learn each other's language. When the preschool was established in 2004 the teachers - Aviva, the native Hebrew-speaking teacher and Sokeina, the native Arabic-speaking teacher - were told to separate the languages according to the teacher, that is, each teacher should stick to her native language. However, quite soon Aviva and Sokeina found that this parallel monolingualism was not working. It became evident that both ethnic groups of children - but especially the Jewish children - were showing very slow progress in the second language. They found that the language separation model resulted in the Jewish children passively waiting for a translation, which led to disengagement. The teachers reported that after a number of months they decided to both speak in both languages; in other words, they gave up language separation by person and started to apply flexible language practices in the classroom (Menken and García 2010). In the interviews both teachers frequently addressed this reconsideration of the initial language separation model - with translation as a main bilingual teaching strategy- and the adoption of 
flexible bilingual practices, and stressed that the rationale was based on experience rather than research.

Further, it was obvious to the teachers that, as a minority language, Arabic should be given more emphasis and should 'be more prominent' in the classroom than the majority language, Hebrew (cf. two-way immersion classrooms presented in Genesee and Lindholm-Leary 2013):

Sokeina (the Arabic language teacher): for Arab students the Hebrew language is easier because they hear it at home and on television and while shopping Hebrew exists in the background for Jewish children we start with the simpler things (.) thus I try to give a lot of Arabic in order for the Jewish children to understand (.) the Arab children already understand they recognize and speak the language [= Hebrew] and they have heard it before so I try to emphasize Arabic so it will be more prominent

Similarly to the Arabic-Hebrew setting, the Russian-Finnish preschool also consisted of a heterogeneous group of children in which the development of both Russian and Finnish, either as L1 or as L2, was to be supported in all children. In previous times, the linguistic backgrounds of the children had been more homogeneous, as explained in the following quote by Lena, the native Russian-speaking teacher:

Lena (the Russian language teacher): when [the preschool] was opened we had only Finnish children, who were taught Russian (.) Russian-speaking teachers didn't speak Finnish and back then the bilingual teacher had a huge role as translator and a link between the child and the Russian teacher in their communication (.) then the immigration began and [---] now we have so many Russian children and bilinguals whose parents want to support the native Russian language (.) that's how the roles changed and we started to pay more attention to Finnish language for bilinguals and for the Russian-speaking children

Lena thus explained that, in previous times, the native Russian-speaking teachers used to communicate only in Russian while the bilingual teachers had the role of translators 
and L2 instructors. The current situation, with a more heterogeneous group of children, had, however, resulted in changes in practices: the Russian- and Finnish-speaking teachers used their own native languages and - as will be evident below - to some extent also the other language, and flexibly switched between the languages according to the needs and competencies of the individual child. Importantly, the needs expressed by the parents of Russian-speaking and Russian-Finnish bilingual families served as a significant force for change: these parents asked for increased instruction in Finnish in addition to Russian.

\section{Responsible Code-switching}

From the teachers' interviews it was clear that the teachers were aware of how they allocated their use of languages and that they were constantly monitoring their own use, which is characteristic of responsible code-switching (García 2009; Van der Walt, Mabule, and de Beer 2001). One common characteristic among the teachers was the avoidance of direct translation, or what García $(2009,302)$ refers to as ‘co-languaging’. Montague (1997) and Lewis, Jones, and Baker (2012) have claimed that translation as a main strategy leads to L2 learners passively waiting for a translation instead of being actively involved in L2 learning. Quite the same experience led Aviva to abandon colanguaging in the Arabic-Hebrew classroom:

Aviva (the Hebrew language teacher): when you translate (.) as I see it (.) what happens with children is that they learn a very important lesson in patience and waiting and disengagement because they know that when Sokeina [= Arabic language teacher] is talking their job is to be quiet (.) they [= Hebrew-speaking children] didn't listen when there was a translation (.) they didn't even look out for words that they could connect to, so they would have an anchor in the conversation

Also Johanna avoided direct translation and reported that she never reproduced the 
exact wording in the other language. Instead, she saw to it that there was semantic content overlap between the utterances - 'it is connected' - in the two languages. Johanna explained that direct translation would cause her too much work and also feel awkward. Moreover, in the Russian-Finnish context, the Russian language teacher Lena explained that she avoided translating content into the child's L1 because she wanted to involve the children: 'we try to get the kids involved and prefer to show and explain in action instead of translating what we want from the child'.

One communicative purpose of code-switching reported by the teachers was gaining and sustaining the children's attention. For this purpose the children's L1 was used. Johanna, for example, reported switching into Finnish whenever she needed to get the children's attention: 'I bring in Finnish when I want them to be on their toes'. A switch from L2 to L1 in order to cause surprise, get attention and ensure understanding was also reported by the Russian language teacher, Lena, who said she switched into Finnish to keep the Finnish-speaking children engaged and active and to prevent boredom and fatigue. Once their attention was caught, she said she switched back into Russian to explain to them what would happen next (e.g. explaining activities and giving instructions). Also Tomi, the bilingual Russian-Finnish teacher, had carefully considered how to use the two languages. In the case of L1 Russian-speaking children, Tomi sometimes switched from Finnish to Russian in order to negotiate meaning and facilitate the child's understanding. This happened in situations in which he thought the child would not understand him in Finnish at all.

In the Finnish-Swedish context, Johanna said that she used children’s L1 Finnish when it was important that the children understood completely, like when engaging children in conversation, discussing abstract topics and giving important information or instructions that needed to be clearly understood (cf. Macaro 2006). The children’s L2, 
Swedish, on the other hand, she used for concrete content and topics she knew they would be able to follow.

Pavlenko (2004) has shown that there is a close connection between emotional content and first language use. In the quotation below, Johanna describes how she came to realize that she should use Finnish (the children's L1) in emotionally loaded situations:

\footnotetext{
Johanna (the bilingual Finnish-Swedish teacher): so back then if there was a conflict [between children] for instance I went there to try to resolve it using Swedish (.) but they didn’t understand at all ((gives a laugh)) when I used it to express emotions (.) so I said it in Finnish (.) I pretty soon gave up doing that [=speaking Swedish] since it felt very awkward
}

Lena also reported that she switched from Russian (the children's L2) to Finnish (their L1) in cases of conflict between children or whenever a child was at risk. Moreover, at the beginning of the school year, when she met the Finnish-speaking children for the first time, she used Finnish to get the 'child's trust' and to make contact with the child (cf. Macaro 2006). After this contact had been established and the child had made some progress in Russian she said that then 'you can switch and elaborate your idea in Russian’.

\section{Contextual and Linguistic Supports}

Contextual and linguistic supports (scaffolding structures) have been shown to be essential to enhancing understanding in bilingual pedagogy (see e.g. García 2009, 329336). The concept of scaffolding was first set out by Bruner (1986), a follower of Vygotsky (1978, 1987). Within the context of L2 instruction, the child's L2 development is scaffolded by the teacher so that the child can participate at the level he or she is capable of. Scaffolding includes diverse mediation strategies such as the use of 
body language, contextualization, the verbalization of actions, and the repetition of words and routines, and it was used by the teachers in our study 'to offer meaningful instructional support' (Van der Walt, Mabule, and De Beer 2001, 299). By way of example, Johanna's speech was very deliberate, and certain key words were phonologically stressed, resembling what is sometimes referred to as 'motherese' (Snow 1972) or ‘sheltered instruction’ (e.g., Gort and Pontier 2013). The Russian language teacher, Lena, explained that she used non-verbal means and verbalizing actions in order to involve the L2-children in activities.

Tomi, the bilingual Russian-Finnish teacher, reported the use of similar types of scaffolding techniques to those used by the teachers in the study by Gort and Pontier (2013). One of Tomi’s ways of introducing Finnish as L2 to Russian-speaking children was to gradually increase the linguistic complexity of his utterances. For example, starting out with 'käsienpesulle' (literally, to the hand-washing) and supporting the child's understanding by showing with his own hands how to do it and pointing to the wash-room, the next step might be to say 'mene käsienpesulle' (go to the handwashing), and later 'mene pesemään kädet' (go and wash your hands).

To enhance understanding of the L2, some teachers used intra-sentence codeswitching, a scaffolding technique that has also been observed in other bilingual classrooms (eg. García 2009; Gort and Pointier 2013; Hickey, Jewish, and Baker 2014). In the Arabic-Hebrew context Sokeina explained how she used to gradually immerse the Jewish children in Arabic by applying intra-sentence code-switching from Arabic to Hebrew to support children’s understanding:

Sokeina (the Arabic language teacher): this is the first time that they have heard Arabic a new language for them so I feel the need to include a little from the Hebrew language include Hebrew words in order for them to understand, and not get lost, and [I don't want them] to not understand the entire sentence 
In the above quote, Sokeina showed how inserting 'a little from the Hebrew language' within the Arabic sentence helped her to negotiate meaning. She also reported using code-switching when she could not rely on non-linguistic strategies and visualization to illustrate a new word or to present a concept in the L2 and also to highlight the semantic closeness between the languages (cognates). Identifying cognates has been shown to result in enriched meaning-making across languages and to reinforce metalinguistic awareness (García and Wei 2014, 109). Aviva further explained how both she and Sokeina made use of intra-sentence code-switching in order to keep the children's attention:

Aviva (the Hebrew language teacher): Sokeina will talk talk talk but she will include some Hebrew words while she's speaking in Arabic and I will speak in Hebrew and include some Arabic words in order for the children to stay with us all the time to be in a dialogue with us all the time to be in a dialogue with the language all of the time

\section{Adjusting to Individual Children}

In the case of bilingual language education, sensitivity to a child's individual needs is important, and this calls for multiple competencies on the adults' part (for a research review, see Genesee, Paradis, and Crago 2011). Adjustment to the characteristics of individual children was important to all the teachers and something they frequently elaborated on in the interviews. Tomi referred to some shy children and remarked that they preferred him to speak their L1, Russian, with them:

Tomi (the bilingual Russian-Finnish teacher): the children are very different (.) some children are very shy, they are very emotional (.) because they know that I can speak Russian because they have heard me speaking Russian they think that I should speak Russian with them because they don't know Finnish and they want to hear Russian from me and I must be very careful when I talk to them 
Tomi believed that 'there is no method that is the right one for everybody' and that 'one size does not fit all'. He gave an example of a young boy who did not understand a particular grammatical difference between Finnish and Russian until Tomi translated a crucial verb. He added that if the boy were older, the teacher could, rather than providing a translation of the word, explain to him what the differences between the meaning and form of the Russian and Finnish words were. Also Johanna explained that age mattered: 'we have one-year-olds who don’t have language [= haven’t started to speak] so then I don't speak so much Swedish'.

Tomi did a lot of language work with children with special needs. Johanna too expressed sensitivity to how much and how she used Swedish (their L2) with children who were having speech therapy:

Johanna (the bilingual Finnish-Swedish teacher): so I have maybe been a bit careful (.) well we don't have any children with a registered disability but we have a large number of children who get speech therapy (.) I use Swedish [with them] but very simple Swedish and repetitions

Tomi and Johanna thus shared the belief that teachers' L2 use requires special attention when working with children with special needs.

The children in the Arabic-Hebrew and the Russian-Finnish contexts were being prepared for bilingual schooling and it was therefore important for the teachers to follow the bilingual development of each child and, if necessary, support a child's language development in his/her L2. However, Lena pointed out in the following quote that it was equally important to support children’s L1. A linguistically diverse group that includes children with different needs demands flexibility and creativity:

Lena (the Russian language teacher): I have a feeling that some [children] don't understand while others are bored (.) then I have to give an advanced exercise to a Russian child quickly and then move on to the bilingual children and give them 
something easy so that they remain interested so that they can participate in the lesson and won't think of it as something difficult because they have other questions and exercises and not only one question for all (.) that's very difficult to take into account already when planning a lesson (.) it comes spontaneously during the lesson (.) there might be a situation where you forget what you have planned and you have to play around it especially if the Finnish children are interested (.) then you have to change the task

The concern expressed by Lena was addressed also in a recent study by Hickey, Jewish, and Baker (2014), who claimed that educators in bilingual classrooms have to recognize the linguistic needs of L1 speakers and offer them sufficient linguistic enrichment.

\section{Role-modelling}

Baker $(2009,140)$ acknowledges the importance of teachers as role models to children in bilingual education. According to Baker, one of the key issues is whether the staff use both of their languages and encourage children to do the same. Johanna was fluent in both Finnish and in Swedish and she wanted the children to feel that it was natural that she used both languages with them:

\footnotetext{
Johanna (the bilingual Finnish-Swedish teacher): [it] made me understand that it is kind of (.) 'children are not fools you know' ((laughs)) (.) that it’s common that a person can use many languages and (.) it's pretty natural to them that I use two languages
}

Although she herself initially found it difficult not to separate the languages (cf. discussion above), the children did not: 'children are not fools ... a person can use many languages ... it’s ... natural to them’ (see also Palviainen and Mård-Miettinen 2015).

The Hebrew language teacher, Aviva, wanted to improve her L2 Arabic and Sokeina supported her efforts. Sokeina stressed that Aviva's explicit efforts to learn and use Arabic with the children increased the Jewish children's consciousness of belonging 
to the majority language group, increased their interest in the Arabic language, and apparently affected their motivation to acquire it:

Sokeina (the Arabic language teacher): in order to promote the Arabic language we also need Jewish teachers to promote Arabic in conversation (.) we are the model if Jewish children and also the Arabs see that it is important then they will start to speak they will have motivation they will want to imitate us (.) children see and hear adults who like the children are trying to speak a language

Aviva thus served as a promoter of the minority language (Arabic) among the majority language (Hebrew) speaking children. She also said how important it was for her to learn Arabic during the first years of her teaching, in parallel with the Hebrew-speaking children, in order to set them a good example. She thus acted as a model language learner. A similar motive was found in Lena, who besides her native language, Russian, also knew Finnish. She particularly stressed the importance of the Russian teachers daring to use the L2 (Finnish) despite making mistakes in it. In this way, making mistakes in the language was completely legitimized, and this also empowered the Finnish-speaking children to use their L2 (Russian):

Lena (the Russian language teacher): nowadays almost every Russian teacher speaks some Finnish and can translate a little and can say things themselves (.) they all more or less incorporate a model of a bilingual speaker for children to hear and see that the teacher also speaks two languages (.) some worse and some better (.) I think that then the [Finnish] children are less shy to speak in Russian

Lena believed that in order to teach children to use two languages, preschool teachers have to be multicultural themselves and speak both the languages that are used in the preschool. She praised the model of the Russian-Finnish preschool, in which there were 'constantly two languages present from dawn to dusk'. Johanna also considered it important that the children should feel that two languages was the natural state of affairs 
in the pre-school classroom. In the second year of the project, the new bilingual teacher and she were jointly 'keeping [the idea of] there being two languages in the air' all the time so that the use of Swedish 'doesn’t only happen on Monday mornings'.

\section{Summary}

The descriptions the teachers gave of their bilingual practices and the explanations they gave for them revealed many similarities across the diverse contexts. In all three settings the teachers reported that they had changed language practices over time and their use of languages had become more flexible. The reasons for this varied across the contexts: the teacher's dissatisfaction with mechanical language showers in the case of the Finnish-Swedish preschool, dissatisfaction with the children's progress in the L2 in the Israeli context, and changes in the demographic characteristics of the children and their linguistic background in the case of the Russian-Finnish preschool.

As far as the use of two languages was concerned, the teachers relied on responsible code-switching. None of them believed in or employed direct translation (co-languaging) as a general strategy, nor in teaching monolingually. The teachers monitored how they used the two languages, including switching between them, for functions such as facilitating understanding of the new language, getting or sustaining attention, introducing abstract topics, giving instructions, or handling emotional content or conflicts (for similar findings in a US context with bilingual secondary school teachers, see García and Wei 2014, 111). Moreover, in parallel with the findings of Gort and Pointier (2013) and Hickey, Jewish, and Baker (2014), the preschool teachers were found to employ scaffolding techniques to increase understanding and to encourage children to use the L2. They made use of the verbalization of actions and repeated routines (Johanna); a gradual increase in syntactical complexity in the L2 (Tomi); and intra-sentential code-switching to negotiate meaning and semantic content (Tomi, 
Sokeina and Aviva). These practices could be defined as 'the strategic use of multilingual pedagogies ... in order to scaffold students’ learning’ (Weber 2014, 183184). Moreover, the teachers reported the importance of themselves acting as models for the children of a simultaneous bilingual language user (Johanna) and a majority language speaker using a minority language (Johanna, Aviva). Aviva and Lena also thought it was important to be an L2 learner in order to empower and encourage the L1 children to use the L2 themselves.

Table 2 presents a summary and description of the findings according to the thematic categories as they emerged from the interviews, the teachers' descriptions of their flexible language practices and the teachers' explanations of these practices. It must be noted that not all the teachers employed all the practices, nor did they all provide the same explanations. Rather, the table seeks to show general tendencies across the three distinct research settings.

[Table 2 near here]

\section{Conclusions}

This cross-cultural study aimed to examine how teachers responded to the challenges that arose when implementing a bilingual education model within the context of preschool education in Finland (Finnish-Swedish and Russian-Finnish contexts) and Israel (an Arabic-Hebrew context). With regard to the broader theoretical context of early bilingual education, our data show that despite the different socio-cultural and socio-linguistic contexts of the target bilingual settings, there were similarities in the way the teachers reflected on their language practices and the need they felt to apply flexible bilingual practices in the classroom. These similarities are remarkable, particularly considering the fact that the flexible bilingual practices were developed 
over time through experience, and were not taught in any teachers’ programme. The practices that developed over time were convergent with other flexible bilingual approaches in the teaching of school-age bilingual children, in which strict language separation practices have been reconsidered (Creese and Blackledge 2010; Cummins 2005; García and Wei 2014).

The teachers showed agency and realized a capacity to act upon their world (Holland et al. 1998, 42), in that they purposefully and reflectively modified the initially defined models of working, which were built on language separation, into more flexible bilingual practices. They gave several reasons for the changes in their ways of working, one of which was heterogeneity among the children: the teachers reported the need for creative and flexible approaches in order to negotiate differences in the children's linguistic backgrounds and emotional, cognitive or social needs. In addition to children's individual needs, the teachers also reported that they had to take into account contextual factors such as the educational institution (curricula, superiors), communities (e.g. minority and majority language speakers, parents) and society (such as norms, ideology, politics) (Lemberger 1997; Ricento and Hornberger 1996). Thus, their choice of language practices was to a great extent pragmatically and contextually driven.

We can also conclude that besides offering language input for language learning purposes, the teachers wanted the children to experience bilingual practices as well as bilingual speakers as something natural, mirroring the multilingualism of the $21^{\text {st }}$ century (García 2009, 309). They also wanted to assign to both the languages in question a similar status and not to connect a certain language and its use only to one specific activity, person, or point in time.

Ricento and Hornberger (1996) contextualize the work of teachers and point out the impact of ideologies, culture and ethnicity on their undertakings. These aspects also 
appear in the reflections of the teachers in the present study. Both the teachers in the Arabic-Hebrew preschool as well as Johanna in the Finnish-Swedish context stressed the importance of raising the status and use of a minority language, Arabic and Swedish respectively, and of contributing to positive attitudes towards a minority language among majority language speakers. The findings concerning changes over time also reveal the power of personal ideologies, in terms of both changing one's own practices and challenging prevailing ideologies as represented by society or by superiors.

The similarities across teachers and contexts evidenced in our data have important implications for the field. The shared experience of the bilingual preschool teachers opens up the way to mutual learning and to viewing bilingual teachers not as separate and unrelated individuals each limited to their own context, but as a community of practice. Such a development could encourage early childhood practitioners from other educational contexts and countries to critically examine their current language practices and models and perhaps renegotiate and modify them. By exploring the teacher's role in realizing preschool bilingual pedagogy, the study contributes to the still limited data on teachers' agency in early bilingual development and education. In addition, it throws light on the complexity of a bilingual teacher's task: as Baker (2009, 114), drawing on Benson (2004), points out, the teacher needs to be at the same time 'positive towards students' language and cultural backgrounds, sensitive to their home and community contexts, responding to children's language and cultural needs, celebrating diversity and recognizing the linguistic and cultural gifts of such children’. Besides acknowledging teachers and their complex tasks, this quote makes evident the need for further research in which bilingual education and teachers are compared across different sociolinguistic settings, since the external factors and conditions affecting teachers’ daily language work may vary considerably. Importantly, 
further research is needed that takes into account the particular conditions which obtain in preschool education. The early childhood years are a critical time in children's bilingual development and in their development as bilingual members of the community.

References

Amara, M. H. 2002. “The Place of Arabic in Israel.” International Journal of the Sociology of Language 158: 53-68. doi: 10.1515/ijsl.2002.051

Arthur, J., and P. Martin. 2006. “Accomplishing Lessons in Postcolonial Classrooms: Comparative Perspectives from Botswana and Brunei Darussalam.” Comparative Education 42 (2): 177-202. doi: 10.1080/03050060600628009

Baker, C. 2009. “Becoming Bilingual through Bilingual Education.” In Handbook of multilingualism and multilingual communication, edited by P. Auer, and L. Wei, 131-152. Berlin: Mouton de Gruyter.

Bekerman, Z. 2005. “Complex Contexts and Ideologies: Bilingual Education in Conflict-Ridden Areas.” Journal of Language, Identity, and Education 4 (1): 120. doi: 10.1207/s15327701jlie0401_1

Bekerman, Z., and M. Tatar. 2009. "Parental Choice of Schools and Parents’ Perceptions of Multicultural and Co-existence Education: The Case of the Israeli Palestinian-Jewish Bilingual Primary Schools.” European Early Childhood Education Research Journal 17 (2): 171-187. doi:

$10.1080 / 13502930902951304$ 
Benson, C. 2004. “Do We Expect too much of Bilingual Teachers? Bilingual Teaching in Developing Countries.” International Journal of Bilingual Education and Bilingualism 7 (2/3): 204-221. doi: 10.1080/13670050408667809

Boyd, S., and Å. Palviainen. 2015. "Building Walls or Bridges? A Language Ideological Debate About Bilingual Schools in Finland.” In Language Policies in Finland and Sweden. Interdisciplinary and Multi-sited Comparisons, edited by M. Halonen, P. Ihalainen and T. Saarinen, 57-89. Bristol: Multilingual Matters.

Braun, V., and V. Clarke. 2006. “Using Thematic Analysis in Psychology.” Qualitative Research in Psychology 3: 77-101. doi: 10.1191/1478088706qp063oa

Bruner, J. 1986. Actual Minds, Possible Worlds. Cambridge, MA: Harvard University Press.

Conteh, J. 2007. “Opening Doors to Success in Multilingual Classrooms: Bilingualism, Codeswitching and the Professional Identities of Ethnic Minority Primary Teachers.” Language and Education 21 (6): 457-472. doi: 10.2167/le711.0

Creese, A., and A. Blackledge. 2010. "Translanguaging in the Bilingual Classroom: A Pedagogy for Learning and Teaching?” The Modern Language Journal 94: 103115. doi: 10.111/j.1540-4781.2009.00986.x

Creese, A., and A. Blackledge. 2011. "Separate and Flexible Bilingualism in Complementary Schools: Multiple Language Practices in Interrelationship.” Journal of Pragmatics 43: 1196-1208. doi: 10.1016/j.pragma.2010.10.006

Cummins, J. 2005. “A Proposal for Action: Strategies for Recognizing Heritage Language Competence as a Learning Resource within the Mainstream Classroom.” The Modern Language Journal 89 (4): 585-592. 
Cummins, J. 2014. "Rethinking Pedagogical Assumptions in Canadian French Immersion Programs.” Journal of Immersion and Content-Based Language Education 2 (1): 3-22. doi: 10.1075/jicb.2.1.01cum

García, O. 2009. Bilingual Education in the 21st Century. West Sussex: WileyBlackwell.

García, O. 2013. “From Diglossia to Transglossia: Bilingual and Multilingual Classrooms in the 21th Century." In Bilingual and Multilingual Education in the 21th Century. Building on Experience, edited by C. Abello-Contesse, P.M. Chandler, M.D. López-Jiménez, and R. Chacón-Beltrán, 155-175. Bristol: Multilingual Matters.

García, O., and L. Wei. 2014. Translanguaging. Language, Bilingualism and Education. Basingstoke: Palgrave.

Gass, M. S., and A. Mackey. 2000. Stimulated Recall Methodology in Second Language Research. Mahwah, NJ: Lawrence Erlbaum Associates.

Genesee, F., and K. Lindholm-Leary. 2013. “Two Case Studies of Content-Based Language Education.” Journal of Immersion and Content-Based Language Education 1 (1): 3-33. doi: 10.1075/jicb.1.1.02gen

Genesee, F., J. Paradis, and M. B. Crago. 2011. Dual Language Development and Disorders: A Handbook on Bilingualism and Second Language Learning. Baltimore: Paul H. Brookes.

Gort, M., and R. W. Pontier. 2013. "Exploring Bilingual Pedagogies in Dual Language Preschool Classrooms.” Language and Education 27 (3): 223-245. doi: $10.1080 / 09500782.2012 .697468$

Heller, M. 2007. “Bilingualism as Ideology and Practice.” In Bilingualism: A Social Approach, edited by M. Heller, 1 - 22. Basingstoke: Palgrave Macmillan. 
Hickey, T. M., G. Jewish and C. Baker. 2014. “How Deep Is Your Immersion? Policy and Practice in Welsh-Medium Preschools with Children from Different Language Backgrounds.” International Journal of Bilingualism and Bilingual Education 17 (2): 215-234. doi: 10.1080/13670050.2013.866629

Holland, D., W. Lachicotte Jr., D. Skinner, and C. Cain. 1998. Identity and Agency in Cultural Worlds. Cambridge, Mass: Harvard University Press.

Hult, F. M., and S. Pietikäinen. 2014. "Shaping Discourses of Multilingualism through a Language Ideological Debate: The Case of Swedish in Finland.” Journal of Language and Politics 13 (1): 1-20. doi: 10.1075/jlp.13.1.01hul

Lemberger, N. 1997. Bilingual Education: Teachers' Narratives. Mahwah, NJ: Lawrence Erlbaum Associates.

Lewis, G., B. Jones, and C. Baker. 2012. “Translanguaging: Developing Its Conceptualisation and Contextualisation.” Educational Research and Evaluation: An International Journal on Theory and Practice 18 (7): 655-670. doi: 10.1080/13803611.2012.718490

Lindgren, A.-R., K. Lindgren, and M. Saari. 2011. "From Swedish to Finnish in the 19th Century: A Historical Case of Emancipatory Language Shift.” International Journal of the Sociology of Language 209: 17-34. doi: 10.1515/ijsl.2011.019

Lähteenmäki, M., and S. Pöyhönen. 2015. “Language Rights of the Russian-Speaking Minority in Finland: Multi-sited Historical Arguments and Language Ideologies.” In Language Policies in Finland and Sweden. Interdisciplinary and Multi-sited Comparisons, edited by M. Halonen, P. Ihalainen, and T. Saarinen, 90-115. Bristol: Multilingual Matters. 
Macaro, E. 2006. “Code-switching in the L2 Classroom: A Communication and Learning Strategy.” In Non-native Language Teachers: Perceptions, Challenges and Contributions to the Profession, edited by E. Llurda, 63-84. New York: Springer.

Maybin, J., and K. Tusting. 2011. “Linguistic Ethnography.” In Routledge Handbook of Applied Linguistics, edited by J. Simpson, 515-528. London: Routledge.

Mehistö, P., D. Marsh, and M. J. Frigols. 2008. Uncovering CLIL. Content and Language Integrated Learning in Bilingual and Multilingual Education. Oxford: Macmillan.

Menken, K., and O. García, eds. 2010. Negotiating Language Policies in Schools: Educators as Policymakers. London: Routledge.

Montague, N. S. 1997. “Critical Components for Dual Language Programs.” Bilingual Research Journal 21 (4): 409-417. doi: 10.1080/15235882.1997.10162713

Palviainen, Å. and K. Mård-Miettinen. 2015. “Creating a Bilingual Pre-school Classroom: The Multilayered Discourses of a Bilingual Teacher.” Language and Education 29 (5): 381-399. doi: 10.1080/09500782.2015.1009092

Pavlenko, A. 2004. “'Stop Doing That, ia komu skazala!': Emotions and Language Choice in Bilingual Families.” Journal of Multilingual and Multicultural Development 25 (2-3): 179-203. doi: 10.1080/01434630408666528

Rampton, B., K. Tusting, J. Maybin, R. Barwell, A. Creese, and V. Lytra. 2004. “Linguistic Ethnography: A Discussion Paper.” Accessed 6 October 2014. http://www.lancaster.ac.uk/fss/organisations/lingethn/documents/discussion_pap er_jan_05.pdf 
Ricento, T., and N. H. Hornberger. 1996. "Unpeeling the Onion: Language Planning and Policy and the ELT Professional.” TESOL Quarterly 30 (3): 401-427. doi: $10.2307 / 3587691$

Shohamy, E. 2010. “Cases of Language Policy Resistance in Israel's Centralized Educational System.” In Negotiating Language Policies in Schools: Educators as Policymakers, edited by K. Menken and O. García, 182-197. New York: Routledge.

Snow, C. 1972. “Mothers' Speech to Children Language Learning.” Child Development 43: 549-565.

Statistics of Finland 2014. Accessed November 242015. http://tilastokeskus.fi/tup/suoluk/suoluk_vaesto_en.html

Swain, M., and S. Lapkin. 2013. “A Vygotskian Sociocultural Perspective on Immersion Education: The L1/L2 Debate.” Journal of Immersion and ContentBased Language Education 1 (1): 101-129. doi: 10.1075/jicb.1.1.05swa

Van der Walt, C., R. Mabule, and J. J. De Beer. 2001. "Letting the L1 in by the Back Door: Code Switching and Translation in Science, Mathematics and Biology Classes.” Journal of Language Teaching 35 (2-3): 123-134.

Vygotsky, L. S. 1978. Mind in Society: The Development of Higher Psychological Processes. Cambridge, MA: Harvard University Press.

Vygotsky, L. S. 1987. Thinking and Speech. In The Collected Works of L.S. Vygotsky, Vol 1, Problems of General Psychology, edited by R. W. Rieber and A. S. Carton, 39-285. New York: Plenum Press.

Weber. J.-J. 2014. Flexible Multilingual Education. Putting Children's Needs First. Bristol: Multilingual Matters. 
Table 1. The three research settings described according to the crucial components of bilingual education, as presented by Baker (2009, 137-143).

\begin{tabular}{|c|c|c|c|}
\hline & $\begin{array}{l}\text { The type of child and } \\
\text { language balance }\end{array}$ & $\begin{array}{l}\text { The aims of bilingual } \\
\text { education }\end{array}$ & $\begin{array}{l}\text { Balance of languages in the } \\
\text { classroom (teachers' use) }\end{array}$ \\
\hline $\begin{array}{l}\text { Finnish- } \\
\text { Swedish } \\
\text { (Finland) }\end{array}$ & $\begin{array}{l}\text { 100\% majority } \\
\text { language children } \\
\text { (Finnish) }\end{array}$ & $\begin{array}{l}\text { - to introduce Finnish- } \\
\text { speaking children to } \\
\text { Swedish and mediate } \\
\text { positive attitudes } \\
\text { towards Swedish } \\
\text { - to prepare children for } \\
\text { mainstream } \\
\text { monolingual Finnish } \\
\text { L1 schooling }\end{array}$ & $\begin{array}{l}\text { provision of both } \\
\text { languages flexibly and in } \\
\text { comparable amounts } \\
\text { (50:50) by bilingual } \\
\text { teacher(s) and mainly } \\
\text { Finnish by native } \\
\text { Finnish-speaking teachers }\end{array}$ \\
\hline $\begin{array}{l}\text { Arabic- } \\
\text { Hebrew } \\
\text { (Israel) }\end{array}$ & $\begin{array}{l}\text { - } 60 \% \text { minority } \\
\text { language children } \\
\text { (Arabic) } \\
\text { - } 40 \% \text { majority } \\
\text { language children } \\
\text { (Hebrew) }\end{array}$ & $\begin{array}{l}\text { - } \text { to facilitate intergroup } \\
\text { contact and make } \\
\text { possible positive } \\
\text { attitudes and relations } \\
\text { between Arabs and } \\
\text { Jews } \\
\text { - to prepare children for } \\
\text { bilingual schooling in } \\
\text { an Arabic-Hebrew } \\
\text { elementary school }\end{array}$ & $\begin{array}{l}\text { provision of both } \\
\text { languages flexibly and in } \\
\text { comparable amounts } \\
\text { (50:50) by a native } \\
\text { Arabic-speaking teacher } \\
\text { and a native Hebrew- } \\
\text { speaking teacher }\end{array}$ \\
\hline $\begin{array}{l}\text { Russian- } \\
\text { Finnish } \\
\text { (Finland) }\end{array}$ & $\begin{array}{l}\text { - } 33 \% \text { minority } \\
\text { language children } \\
\text { (Russian) } \\
\text { - } 33 \% \text { majority } \\
\text { language children } \\
\text { (Finnish) } \\
\text { - } 33 \% \text { bilingual } \\
\text { children } \\
\text { (Russian+Finnish) }\end{array}$ & $\begin{array}{l}\text { - to encourage bilingual } \\
\text { education among } \\
\text { children from different } \\
\text { backgrounds } \\
\text { - to prepare children for } \\
\text { bilingual schooling in a } \\
\text { Russian-Finnish } \\
\text { elementary school }\end{array}$ & $\begin{array}{l}\text { provision of both } \\
\text { languages flexibly and in } \\
\text { comparable amounts } \\
\text { (50:50) by one bilingual } \\
\text { teacher, mainly Russian } \\
\text { by one native Russian- } \\
\text { speaking teacher, and } \\
\text { mainly Finnish by one } \\
\text { native Finnish-speaking } \\
\text { teacher }\end{array}$ \\
\hline
\end{tabular}


Table 2. Description of and rationale behind the bilingual practices emerging from the teacher interviews across the Finnish-Swedish, Russian-Finnish and Arabic-Hebrew preschool contexts. Thematic categories (What?), description of bilingual practices (How?) and the reasons the teachers gave for using those particular practices (Why?).

\begin{tabular}{|c|c|c|}
\hline What? & How? & Why? \\
\hline \multirow[t]{4}{*}{$\begin{array}{l}\text { Flexible use of two } \\
\text { languages }\end{array}$} & $\begin{array}{l}\text { One teacher uses /All the } \\
\text { teachers use two languages }\end{array}$ & $\begin{array}{l}\text { Emphasize the importance of } \\
\text { both languages }\end{array}$ \\
\hline & $\begin{array}{l}\text { Equal amounts of use of both } \\
\text { languages throughout the day }\end{array}$ & $\begin{array}{l}\text { Encourage positive attitudes } \\
\text { toward a L2 }\end{array}$ \\
\hline & $\begin{array}{l}\text { More emphasis on the } \\
\text { minority language in the } \\
\text { majority-language context }\end{array}$ & $\begin{array}{l}\text { Maximize L2 learning in } \\
\text { linguistically heterogeneous } \\
\text { contexts }\end{array}$ \\
\hline & & $\begin{array}{l}\text { Support the use of a minority } \\
\text { language }\end{array}$ \\
\hline \multirow{7}{*}{$\begin{array}{l}\text { Responsible code-switching } \\
\text { - Avoidance of direct } \\
\text { translation } \\
\text { - Languages used for } \\
\text { different communicative } \\
\text { purposes }\end{array}$} & $\begin{array}{l}\text { Semantically connected use of } \\
\text { two languages, but not exact } \\
\text { translations of content }\end{array}$ & $\begin{array}{l}\text { Ease the bilingual teacher's } \\
\text { work and communication }\end{array}$ \\
\hline & Gaining and sustaining & $\begin{array}{l}\text { Prevent passive waiting for } \\
\text { translation in L1 children }\end{array}$ \\
\hline & of the children's L1 & $\begin{array}{l}\text { Raise the status of the } \\
\text { minority language or L2 }\end{array}$ \\
\hline & $\begin{array}{l}\text { Introducing abstract topics } \\
\text { and giving instructions in the }\end{array}$ & Maximize L2 learning \\
\hline & $\begin{array}{l}\text { children’s L1; concrete and } \\
\text { well-known knowledge in } \\
\text { their L2 }\end{array}$ & $\begin{array}{l}\text { Ensure attention and } \\
\text { understanding; make children } \\
\text { alert to the reception of new }\end{array}$ \\
\hline & Handling emotional content in & information in L2 \\
\hline & & Make the child feel secure \\
\hline \multirow{5}{*}{$\begin{array}{l}\text { Contextual and linguistic } \\
\text { supports } \\
\text { (scaffolding structures) }\end{array}$} & \multirow{3}{*}{$\begin{array}{l}\text { Use of body language, } \\
\text { contextualization, } \\
\text { verbalization of actions, } \\
\text { repetition of words and } \\
\text { routines, deliberate speech }\end{array}$} & $\begin{array}{l}\text { Enhance understanding in the } \\
\text { children's L2 }\end{array}$ \\
\hline & & Scaffold children's L2 use \\
\hline & & Teach the children L2 \\
\hline & $\begin{array}{l}\text { Systematic increase in } \\
\text { linguistic complexity in L2 }\end{array}$ & vocabulary, syntax, semantics \\
\hline & $\begin{array}{l}\text { Ingulstic complexity in LL } \\
\text { Intra-sentential code- } \\
\text { switching }\end{array}$ & $\begin{array}{l}\text { Show sensitivity to what the } \\
\text { children can, and cannot, } \\
\text { understand in their L2 }\end{array}$ \\
\hline
\end{tabular}


(Table 2 continues)

\begin{tabular}{|c|c|c|}
\hline $\begin{array}{l}\text { Adjustments to individual } \\
\text { children }\end{array}$ & $\begin{array}{l}\text { Careful and thoughtful use of } \\
\text { L2 with children with special } \\
\text { needs, different personalities } \\
\text { and ages }\end{array}$ & $\begin{array}{l}\text { 'One size does not fit all': } \\
\text { Work for the individual } \\
\text { child's best and promote } \\
\text { understanding }\end{array}$ \\
\hline & $\begin{array}{l}\text { Monitoring children's L2 } \\
\text { competence and development } \\
\text { and adapting language use } \\
\text { Giving sufficiently rich input } \\
\text { in the children's L1 }\end{array}$ & $\begin{array}{l}\text { Prepare each child for } \\
\text { bilingual schooling and } \\
\text { develop adequate skills in } \\
\text { his/her L1 and L2 }\end{array}$ \\
\hline Role-modelling & $\begin{array}{l}\text { The teacher uses two } \\
\text { languages concurrently and } \\
\text { flexibly } \\
\text { A majority language teacher } \\
\text { also speaks a minority } \\
\text { language } \\
\text { An L1 teacher uses his/her } \\
\text { L2, despite making errors } \\
\text { Both languages are used and } \\
\text { heard on a regular and } \\
\text { integrated basis in the } \\
\text { preschool environment }\end{array}$ & $\begin{array}{l}\text { Mediate positive attitudes } \\
\text { towards (especially minority) } \\
\text { languages, bilingualism, } \\
\text { culture and being a bilingual } \\
\text { speaker } \\
\text { Encourage bilingual and L2 } \\
\text { use in the children }\end{array}$ \\
\hline
\end{tabular}


${ }^{\mathrm{i}}$ Transcription keys:

(.) A brief pause.

[---] Stretches of speech have been omitted.

[= ] Clarification.

Text within [ ] added to complete an utterance syntactically or semantically;

(( )) Extra-linguistic information. 